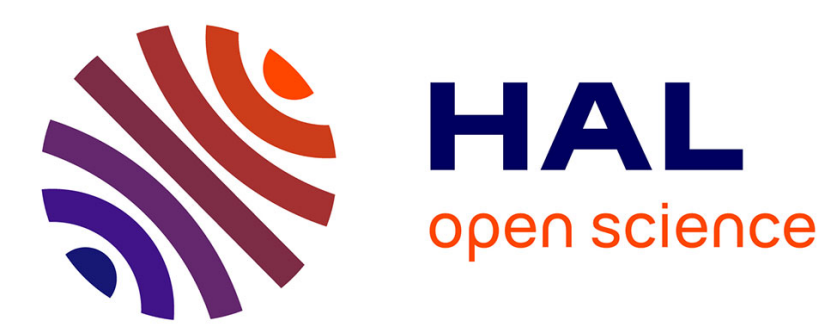

\title{
Refined instrumental variable methods for identifying hammerstein models operating in closed loop
}

Vincent Laurain, Marion Gilson, Hugues Garnier

\section{To cite this version:}

Vincent Laurain, Marion Gilson, Hugues Garnier. Refined instrumental variable methods for identifying hammerstein models operating in closed loop. 48th IEEE Conference on Decision and Control and 28th Chinese Control Conference, Dec 2009, Shanghai, China. pp.314-320. hal-00424135

\section{HAL Id: hal-00424135 \\ https://hal.science/hal-00424135}

Submitted on 14 Oct 2009

HAL is a multi-disciplinary open access archive for the deposit and dissemination of scientific research documents, whether they are published or not. The documents may come from teaching and research institutions in France or abroad, or from public or private research centers.
L'archive ouverte pluridisciplinaire HAL, est destinée au dépôt et à la diffusion de documents scientifiques de niveau recherche, publiés ou non, émanant des établissements d'enseignement et de recherche français ou étrangers, des laboratoires publics ou privés. 


\title{
Refined Instrumental Variable Methods for Identifying Hammerstein Models Operating in Closed Loop
}

\author{
V. Laurain*, M. Gilson*, H. Garnier*
}

\begin{abstract}
This article presents an instrumental variable method dedicated to non-linear Hammerstein systems operating in closed loop. The linear process is a Box-Jenkins model and the non-linear part is a sum of known basis functions. The performance of the proposed algorithm is illustrated by a numerical example.
\end{abstract}

\section{INTRODUCTION}

The need for non-linear identification grows as the studied system complexity increases [14]. Many different approaches were developed to deal with open-loop blackbox model identification, whether they are non parametric, using Volterra series approach [11], [15], semi-parametric using neural network methods and support vector machine classification [16], [3], or parametric such as state dependent parameters [24] or refined instrumental variable [12]. Semiparametric approaches, even if performing efficiently, lack the possibility of giving an a posteriori physical representation of the studied system. On the other hand, transfer function models provide a generic approach to data-based modelling of linear systems, encompass both discrete-time and continuous-time applications and are in an ideal form to interpret serial, parallel connections of sub-systems which often have a physical significance.

Closed-loop systems are widely used in practice and various attempts have been made to handle linear system identification in the presence of feedback. Indeed, closedloop system identification leads to several difficulties due to the correlation between the disturbances and the control signal induced by the loop. Several methods have therefore been developed to cope with this problem see e.g. [18], [20], [5], [25]. An optimal refined instrumental variable method has been presented for closed-loop linear systems in [7].

The problem of non-linear plants operating in closed loop have not received a lot of attention so far. Indeed, this problem is handled only in a few papers as in e.g [6], [10], [2], and [21] but to the best of our knowledge no instrumental variable (IV) method has been developed to deal with this kind of issues. For closed-loop linear identification, a basic IV estimator was first suggested in [22], assuming the knowledge of the controller; the topic was later discussed in more detail in [19]. The present paper extends the refined IV technique theory developed for linear cases presented in [7] to the identification of discrete-time Hammerstein models operating in closed loop. This paper is organized as follows: after the preliminaries, the proposed iterative IV method

\footnotetext{
${ }^{*}$ Centre de Recherche en Automatique de Nancy (CRAN), Nancyuniversité, CNRS, BP 239, 54506 Vandoeuvre-les-Nancy Cedex, France vincent. laurainecran.uhp-nancy.fr
}

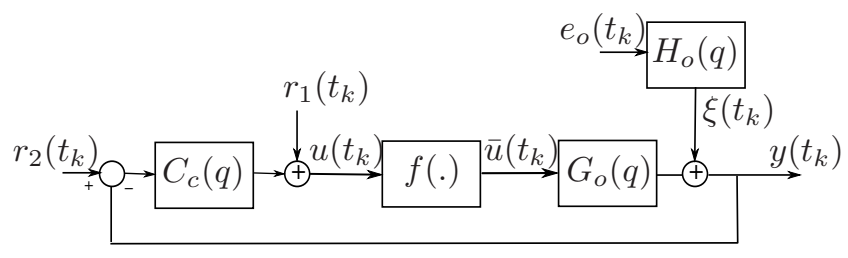

Fig. 1. Closed-loop system

is described in Section III. The detailed algorithm of the method is given in Section IV. Finally, the performance of the proposed algorithm is illustrated through a numerical example in Section V.

\section{PROBLEM DESCRIPTION}

\section{A. System considered}

Consider the stable, SISO closed-loop non-linear system represented in Figure 1 and assume that both command input and output signals, $u\left(t_{k}\right)$ and $y\left(t_{k}\right)$ are uniformly sampled at a constant sampling time $T_{s}$ over $N$ samples.

The controller is supposed to be known, the linear process is Box-Jenkins model and the non-linear function is assumed to be a sum of known basis functions $\gamma_{1}, \gamma_{2}, \ldots, \gamma_{l}$ so that it can be expressed:

$$
\bar{u}\left(t_{k}\right)=\sum_{i=1}^{l} \alpha_{o, i} \gamma_{i}\left(u\left(t_{k}\right)\right) .
$$

Notice first that this system produces the same inputoutput data for any pair $\left(\beta f(u), G_{o}(q) / \beta\right)$. Therefore, to get a unique parametrization, one of the gains of $f(u)$ or $G_{o}(q)$ has to be fixed [4], [1]. Hence, the first coefficient of the function $f($.$) equals to 1$, i.e. $\alpha_{1}=1$ in (1).

Moreover, $\bar{u}\left(t_{k}\right)$ in (1) is an internal variable and is not directly available from data. Using (1), the system $\mathcal{S}$ to be identified is described by the following input-output relationships:

$$
\mathcal{S}\left\{\begin{array}{l}
y\left(t_{k}\right)=G_{o}(q) \bar{u}\left(t_{k}\right)+H_{o}(q) e_{o}\left(t_{k}\right), \\
\bar{u}\left(t_{k}\right)=\sum_{i=1}^{l} \alpha_{o, i} \gamma_{i}\left(u\left(t_{k}\right)\right), \\
u\left(t_{k}\right)=r\left(t_{k}\right)-C_{c}(q) y\left(t_{k}\right),
\end{array}\right.
$$

where $G_{o}(q)$ denotes the process and $C_{c}(q)$ the controller. $u\left(t_{k}\right)$ describes the process input signal, $y\left(t_{k}\right)$ the process output signal. $B_{o}\left(q^{-1}\right)$ and $A_{o}\left(q^{-1}\right)$ are polynomials in the shift operator $q^{-1}\left(q^{-r} x\left(t_{k}\right)=x\left(t_{k-r}\right)\right)$ with respective degree $n_{b}$ and $n_{a}$. This non-linear system can be expressed 
in the following form by combining the first two equations in (2):

$$
\mathcal{S}\left\{\begin{array}{l}
y\left(t_{k}\right)=\sum_{i=1}^{l} G_{o, i}(q) \gamma_{i}\left(u\left(t_{k}\right)\right)+H_{o}(q) e_{o}\left(t_{k}\right), \\
u\left(t_{k}\right)=r\left(t_{k}\right)-C_{c}(q) y\left(t_{k}\right),
\end{array}\right.
$$

where

$$
G_{o, i}(q)=\frac{B_{o, i}\left(q^{-1}\right)}{A_{o}\left(q^{-1}\right)}=\frac{\alpha_{o, i} B_{o}\left(q^{-1}\right)}{A_{o}\left(q^{-1}\right)}
$$

and

$$
r\left(t_{k}\right)=r_{1}\left(t_{k}\right)+C_{c}(q) r_{2}\left(t_{k}\right) .
$$

The method presented is based on the identification of a Box-Jenkins model, where the linear and the noise models are not constrained to have common polynomials. The coloured noise associated with the sampled output measurement $y\left(t_{k}\right)$ has rational spectral density and can be represented by a discrete-time autoregressive moving average ARMA model:

$$
\xi\left(t_{k}\right)=H_{o}(q) e\left(t_{k}\right)=\frac{C_{o}\left(q^{-1}\right)}{D_{o}\left(q^{-1}\right)} e_{o}\left(t_{k}\right)
$$

where $C_{o}\left(q^{-1}\right)$ and $D_{o}\left(q^{-1}\right)$ are polynomials with respective degree $n_{c}$ and $n_{d} . e_{o}\left(t_{k}\right)$ is a zero-mean, normally distributed, discrete-time white noise sequence: $e_{o}\left(t_{k}\right) \sim$ $\mathcal{N}\left(0, \sigma_{e}^{2}\right)$.

Additionally, the controller $C_{c}(q)$ is given by

$$
C_{c}(q)=\frac{Q\left(q^{-1}\right)}{P\left(q^{-1}\right)}=\frac{q_{0}+q_{1} q^{-1}+\cdots+q_{n_{q}} q^{-n_{q}}}{p_{0}+p_{1} q^{-1}+\cdots+p_{n_{p}} q^{-n_{p}}},
$$

with the pair $(P, Q)$ assumed to be coprime.

\section{B. Model considered}

The model set to be estimated, denoted as $\mathcal{M}$ with subsystems $\left(\mathcal{G}_{i}\right)$ and noise $(\mathcal{H})$ models parameterized independently, then takes the form,

$$
\mathcal{M}:\left\{G_{i}(q, \boldsymbol{\rho}), H(q, \boldsymbol{\eta})\right\}, \quad \text { with } i=1 \ldots l
$$

where $\rho$ and $\eta$ are parameter vectors that characterise the system and noise model, respectively. In particular, the system model is formulated in discrete-time terms:

$$
\begin{aligned}
\mathcal{G}: G_{i}(q, \boldsymbol{\rho}) & =\frac{B_{i}\left(q^{-1}, \boldsymbol{\rho}\right)}{A\left(q^{-1}, \boldsymbol{\rho}\right)}, \\
& =\frac{\alpha_{i}\left(b_{1} q^{-1}+b_{2} q^{-2}+\cdots+b_{n_{b}} q^{-n_{b}}\right)}{1+a_{1} q^{-1} \cdots+a_{n_{a}} q^{-n_{a}}},
\end{aligned}
$$

with $i=1 \ldots l$ and the pairs $\left(A, B_{i}\right)$ assumed to be coprime. The associated model parameters are stacked columnwise in the parameter vector,

$$
\boldsymbol{\rho}=\left[\begin{array}{c}
\mathbf{a} \\
\alpha_{1} \mathbf{b} \\
\vdots \\
\alpha_{l} \mathbf{b}
\end{array}\right] \in \mathbb{R}^{n_{\rho}}, \mathbf{a}=\left[\begin{array}{c}
a_{1} \\
a_{2} \\
\vdots \\
a_{n_{a}}
\end{array}\right] \in \mathbb{R}^{n_{a}}, \mathbf{b}=\left[\begin{array}{c}
b_{1} \\
b_{2} \\
\vdots \\
b_{n_{b}}
\end{array}\right] \in \mathbb{R}^{n_{b}}
$$

with $n_{\rho}=n_{a}+n_{b} l$ while the noise model is in discrete-time form

$$
\mathcal{H}: H(q, \boldsymbol{\eta})=\frac{C\left(q^{-1}, \boldsymbol{\eta}\right)}{D\left(q^{-1}, \boldsymbol{\eta}\right)}=\frac{1+c_{1} q^{-1}+\cdots+c_{n_{c}} q^{-n_{c}}}{1+d_{1} q^{-1}+\cdots+d_{n_{d}} q^{-n_{d}}}
$$

where the associated model parameters are stacked columnwise in the parameter vector,

$$
\boldsymbol{\eta}=\left[\begin{array}{llllll}
c_{1} & \cdots & c_{n_{c}} & d_{1} & \cdots & d_{n_{d}}
\end{array}\right]^{T} \in \mathbb{R}^{n_{c}+n_{d}}
$$

Consequently, the noise transfer function takes the usual ARMA model form:

$$
\xi\left(t_{k}\right)=\frac{C\left(q^{-1}, \boldsymbol{\eta}\right)}{D\left(q^{-1}, \boldsymbol{\eta}\right)} e\left(t_{k}\right) .
$$

More formally, there exists the following decomposition of the parameter vector $\boldsymbol{\theta}$ for the whole model,

$$
\theta=\left(\begin{array}{l}
\rho \\
\eta
\end{array}\right)
$$

such that the model can be written in the form

$$
\left\{\begin{array}{l}
y\left(t_{k}\right)=\frac{1}{A\left(q^{-1}, \boldsymbol{\rho}\right)} \sum_{i=1}^{l} B_{i}\left(q^{-1}, \boldsymbol{\rho}\right) \gamma_{i}\left(u\left(t_{k}\right)\right)+\xi\left(t_{k}\right) \\
\xi\left(t_{k}\right)=\frac{C\left(q^{-1}, \boldsymbol{\eta}\right)}{D\left(q^{-1}, \boldsymbol{\eta}\right)} e\left(t_{k}\right) \\
u\left(t_{k}\right)=r\left(t_{k}\right)-C_{c}(q) y\left(t_{k}\right)
\end{array}\right.
$$

with $B_{i}\left(q^{-1}, \boldsymbol{\rho}\right)=\alpha_{i} B\left(q^{-1}, \boldsymbol{\rho}\right), i=1 \ldots l$.

\section{Identification problem}

Under the following assumptions:

A1: The degrees $n_{a}, n_{b}, n_{c}$ and $n_{d}$ are supposed to be known a priori;

A2: The controller $C_{c}$ is supposed to be a priori known and will not be estimated;

A3: $A_{o}\left(q^{-1}\right)$ and $B_{o}\left(q^{-1}\right)$ are coprime;

A4: $r\left(t_{k}\right)$ is not correlated to $e_{o}\left(t_{k}\right)$;

A5: $r\left(t_{k}\right)$ and $y\left(t_{k}\right)$ are stationary signals;

A6: The non-linear basic functions $\gamma_{i}$ as well as the degree $l$ are $a$ priori known and $\gamma_{i}$ are pairwise orthogonal;

The identification problem can be formulated as follows: given $N$ samples of data $\left\{r\left(t_{k}\right), u\left(t_{k}\right), y\left(t_{k}\right)\right\}_{k=1}^{N}$, directly estimate the discrete time parameter vector $\boldsymbol{\theta}$.

\section{INSTRUMENTAL VARIABLE FOR CLOSED-LOOP SYSTEMS}

\section{A. The instrumental variable estimate}

Consider the relationship between process input and output signals which can be written under such a regression form:

$$
y\left(t_{k}\right)=\varphi^{T}\left(t_{k}\right) \boldsymbol{\rho}+v\left(t_{k}\right)
$$

The well-known extended-IV estimate is given by [17]: 


$$
\begin{aligned}
\hat{\boldsymbol{\rho}}_{x i v}(N)=\arg \min _{\boldsymbol{\rho}} \|\left[\frac{1}{N} \sum_{k=1}^{N} L(q) \boldsymbol{\zeta}\left(t_{k}\right) L(q) \boldsymbol{\varphi}^{T}\left(t_{k}\right)\right] \\
-\left[\frac{1}{N} \sum_{t=1}^{N} L(q) \boldsymbol{\zeta}\left(t_{k}\right) L(q) y\left(t_{k}\right)\right] \|_{W}^{2},
\end{aligned}
$$

where $\zeta\left(t_{k}\right)$ is the instrumental vector, $\|x\|_{W}^{2}=x^{T} W x$, with $W$ a positive definite weighting matrix and $L(q)$ a stable prefilter. By definition, when $G_{o} \in \mathcal{G}$, the extended-IV estimate provides a consistent estimate under the following two conditions ${ }^{1}$

- $\overline{\mathbb{E}} L(q) \boldsymbol{\zeta}\left(t_{k}\right) L(q) \boldsymbol{\varphi}^{T}\left(t_{k}\right)$ is full column rank,

- $\overline{\mathbb{E}} L(q) \boldsymbol{\zeta}\left(t_{k}\right) L(q) v\left(t_{k}\right)=0$.

B. Optimal instrumental variable for linear systems in closed loop

Concerning the latest advance in IV method for closedloop systems, a so-called "tailor-made IV algorithm" was proposed in [8], where the closed-loop plant is parameterized using the (open-loop) plant parameters. Then, an optimal (minimal) variance result was developed in the linear closedloop extended IV identification case, revealing consequences for the choice of weights, filters and instruments [9], [7].

Consider the relationship between the process input and output signals in (2) for $u(t)=\bar{u}(t)$,

$$
y\left(t_{k}\right)=G_{o}(q) u\left(t_{k}\right)+H_{o}(q) e_{o}\left(t_{k}\right) .
$$

If the process to be identified belongs to the model set previously defined, then $y\left(t_{k}\right)$ can be written under the regression form:

$$
y\left(t_{k}\right)=\varphi^{T}\left(t_{k}\right) \boldsymbol{\rho}+v\left(t_{k}\right)
$$

where,

$$
\begin{gathered}
\boldsymbol{\varphi}\left(t_{k}\right)=\left[-y\left(t_{k-1}\right) \ldots-y\left(t_{k-n_{a}}\right), u\left(t_{k-1}\right) \ldots u\left(t_{k-n_{b}}\right)\right]_{(20)}^{T}, \\
\boldsymbol{\rho}=\left[a_{1}, \ldots, a_{n_{a}}, b_{1}, \ldots, b_{n_{b}}\right]^{T}
\end{gathered}
$$

and

$$
v\left(t_{k}\right)=A\left(q^{-1}, \boldsymbol{\rho}\right) \xi\left(t_{k}\right) .
$$

It has been shown in that case that the minimum variance estimator can be achieved by the following optimal choice of design variables [9], [7]

$$
\begin{aligned}
& W=I, \\
& \boldsymbol{\zeta}\left(t_{k}\right)=\stackrel{\varphi}{ }\left(t_{k}\right), \\
& L(q)=L^{o p t}(q)=\frac{1}{A_{o}\left(q^{-1}\right) H_{o}(q)} .
\end{aligned}
$$

where $\stackrel{\varphi}{\varphi}\left(t_{k}\right)$ is the noise-free version of $\varphi\left(t_{k}\right)$.

\footnotetext{
${ }^{1}$ The notation $\overline{\mathbb{E}}[]=.\lim _{N \rightarrow \infty} \frac{1}{N} \sum_{t=1}^{N} \mathbb{E}[$.$] is adopted from the$ prediction error framework of [13].
}

C. Instrumental variable for non-linear systems in closed loop

Now consider the relationship between the process input and output signals in (2),

$$
y\left(t_{k}\right)=G_{o}(q) \bar{u}\left(t_{k}\right)+H_{o}(q) e_{o}\left(t_{k}\right) .
$$

If the process to be identified belongs to the model set previously defined, then $y\left(t_{k}\right)$ can be written under the regression form (with $\rho$ as defined in (10)) :

$$
y\left(t_{k}\right)=\varphi^{T}\left(t_{k}\right) \boldsymbol{\rho}+v\left(t_{k}\right)
$$

where,

$$
\begin{gathered}
\boldsymbol{\varphi}\left(t_{k}\right)=\left[\begin{array}{c}
-\mathbf{y}\left(t_{k}\right) \\
\gamma_{1}\left(\mathbf{u}\left(t_{k}\right)\right) \\
\vdots \\
\gamma_{l}\left(\mathbf{u}\left(t_{k}\right)\right)
\end{array}\right], \mathbf{y}\left(t_{k}\right)=\left[\begin{array}{c}
y\left(t_{k-1}\right) \\
y\left(t_{k-2}\right) \\
\vdots \\
y\left(t_{k-n_{a}}\right)
\end{array}\right], \\
\mathbf{u}\left(t_{k}\right)=\left[\begin{array}{c}
u\left(t_{k-1}\right) \\
u\left(t_{k-2}\right) \\
\vdots \\
u\left(t_{k-n_{b}}\right)
\end{array}\right],
\end{gathered}
$$

and

$$
v\left(t_{k}\right)=A\left(q^{-1}, \boldsymbol{\rho}\right) \xi\left(t_{k}\right) .
$$

By logically extending the IV presented in Section IIIB to non-linear systems, we propose to use the following instrumental variable:

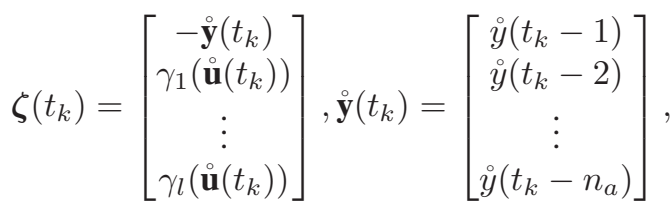

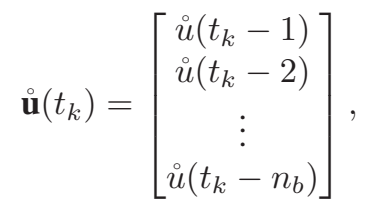

where the noise-free system can be described by:

$$
\stackrel{\mathcal{S}}{ }\left\{\begin{array}{l}
\stackrel{\circ}{y}\left(t_{k}\right)=\sum_{i=1}^{l} G_{o, i}(q) \gamma_{i}\left(\stackrel{\circ}{u}\left(t_{k}\right)\right), \\
\stackrel{u}{u}\left(t_{k}\right)=r\left(t_{k}\right)-C_{c}(q) \grave{y}\left(t_{k}\right)
\end{array}\right.
$$

\section{Remark 1}

It has to be noticed that for the non-linear case, choosing $L(q), \boldsymbol{\zeta}\left(t_{k}\right)$ and $W$ as optimally defined in the linear case does not guarantee the statistical optimality of the estimate. In the present context it can be seen that $n_{\varphi}$ and therefore $n_{\zeta}$ over-parametrizes the system: The number of parameters of the system which equals $n_{a}+n_{b}+l-1$ is less than the number of parameters to be estimated $\left(n_{a}+n_{b} l\right)$ in the associated model.

\section{Remark 2}

None of $A\left(q^{-1}, \boldsymbol{\rho}\right), B_{i}\left(q^{-1}, \boldsymbol{\rho}\right), C\left(q^{-1}, \boldsymbol{\eta}\right)$ or $D\left(q^{-1}, \boldsymbol{\eta}\right)$ is known and only their estimates are available. Therefore, 
refined IV estimation normally involves an iterative (or relaxation) algorithm in which, at each iteration, the 'auxiliary model' used to generate the instrumental variable, as well as the associated prefilter $L(q)$, are updated, based on the parameter estimates obtained at the previous iteration [23].

\section{THE REFINED INSTRUMENTAL VARIABLE ALGORITHM}

Step 1. Initialisation: A simple least square method is used to initialize the algorithm.

$$
\hat{\rho}^{0}=\left[\sum_{k=1}^{N} \boldsymbol{\varphi}\left(t_{k}\right) \boldsymbol{\varphi}^{T}\left(t_{k}\right)\right]^{-1} \sum_{k=1}^{N} \boldsymbol{\varphi}\left(t_{k}\right) y\left(t_{k}\right),
$$

where $\varphi\left(t_{k}\right)$ is given by (28). This yields $B_{i}\left(q^{-1}, \hat{\rho}^{0}\right)$ and $A\left(q^{-1}, \hat{\rho}^{0}\right)$. Denote the corresponding transfer functions

$$
G_{i}\left(q, \hat{\rho}^{0}\right)=\frac{B_{i}\left(q^{-1}, \hat{\rho}^{0}\right)}{A\left(q^{-1}, \hat{\rho}^{0}\right)} .
$$

Set the initial noise model estimates $C\left(q^{-1}, \hat{\eta}^{0}\right)=$ $D\left(q^{-1}, \hat{\eta}^{0}\right)=1$ and $j=1$.

\section{Step 2. Estimate a model based proposed IV}

Generate the filtered instruments according to the model structure at the $j^{\text {th }}$ iteration:

- Compute $L\left(q, \hat{\boldsymbol{\theta}}^{j-1}\right)=\frac{1}{A\left(q^{-1}, \hat{\boldsymbol{\rho}}^{j-1}\right) H\left(q, \hat{\boldsymbol{\eta}}^{j-1}\right)}$,

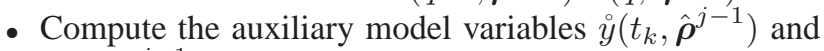
$\stackrel{i}{u}\left(t_{k}, \hat{\boldsymbol{\rho}}^{j-1}\right)$ by simulating the estimated auxiliary model $\stackrel{\mathcal{S}}{(}\left(\hat{\boldsymbol{\rho}}^{j-1}\right)$ :

$$
\left\{\begin{array}{l}
\stackrel{\circ}{y}\left(t_{k}, \hat{\boldsymbol{\rho}}^{j-1}\right)=\sum_{i=1}^{l} G_{o, i}\left(q, \hat{\boldsymbol{\rho}}^{j-1}\right)\left(\gamma_{i}\left(\stackrel{\circ}{ }\left(t_{k}, \hat{\boldsymbol{\rho}}^{j-1}\right)\right),\right. \\
\stackrel{\circ}{u}\left(t_{k}, \hat{\boldsymbol{\rho}}^{j-1}\right)=r\left(t_{k}\right)-C_{c}(q) \grave{y}\left(t_{k}, \hat{\boldsymbol{\rho}}^{j-1}\right),
\end{array}\right.
$$

- Generate the filtered instrument:

$$
\boldsymbol{\zeta}_{f}\left(t_{k}\right)=L\left(q, \hat{\boldsymbol{\theta}}^{j-1}\right) \dot{\boldsymbol{\varphi}}\left(t_{k}, \hat{\boldsymbol{\rho}}^{j-1}\right)
$$

- Generate the filtered regressor and output

$$
\begin{aligned}
& \boldsymbol{\varphi}_{f}\left(t_{k}\right)=L\left(q, \hat{\boldsymbol{\theta}}^{j-1}\right) \boldsymbol{\varphi}\left(t_{k}, \hat{\boldsymbol{\rho}}^{j-1}\right), \text { and } \\
& y_{f}\left(t_{k}\right)=L\left(q, \hat{\boldsymbol{\theta}}^{j-1}\right) y\left(t_{k}\right)
\end{aligned}
$$

- Compute the non-linear closed-loop refined instrumental variable (HCLRIV) estimate:

$$
\hat{\boldsymbol{\rho}}^{j}(N)=\left[\sum_{k=1}^{N} \hat{\boldsymbol{\zeta}}_{f}\left(t_{k}\right) \boldsymbol{\varphi}_{f}^{T}\left(t_{k}\right)\right]^{-1} \sum_{k=1}^{N} \hat{\boldsymbol{\zeta}}_{f}\left(t_{k}\right) y_{f}\left(t_{k}\right)
$$

Step 3. Obtain an estimate of the noise model parameter vector $\eta^{j}$ based on the estimated noise sequence:

- Compute the estimated noise sequence:

$$
v\left(t_{k}\right)=y\left(t_{k}\right)-\sum_{i=1}^{l} \frac{B_{i}\left(q^{-1}, \hat{\boldsymbol{\rho}}^{j}\right)}{A\left(q^{-1}, \hat{\boldsymbol{\rho}}^{j}\right)} \gamma_{i}\left(u\left(t_{k}\right)\right),
$$

- Estimate $\hat{\boldsymbol{\eta}}^{i}$ and therefore $C\left(q^{-1}, \hat{\boldsymbol{\eta}}^{j}\right)$ and $D\left(q^{-1}, \hat{\boldsymbol{\eta}}^{j}\right)$ with an ARMA method using $v\left(t_{k}\right)$ as input. The
ARMA method from the MATLAB identification toolbox is used here.

Step 4. repeat from step 2. Stop when $A\left(q^{-1}, \hat{\boldsymbol{\rho}}\right)$, $B_{i}\left(q^{-1}, \hat{\boldsymbol{\rho}}\right), H(q, \hat{\boldsymbol{\eta}})$ have converged.

Step 5. Compute the estimated $\boldsymbol{\alpha}$ coefficients and $B\left(q^{-1}, \hat{\boldsymbol{\rho}}\right)$ by using a constraint

At the end of the iterative process, the coefficients $\hat{\alpha}_{i}$ can be deduced from the polynomial $\hat{B}_{i}\left(q^{-1}\right)$ since $B_{i}\left(q^{-1}, \boldsymbol{\rho}\right)=\alpha_{i} B\left(q^{-1}, \boldsymbol{\rho}\right)$. In the present case we use a straightforward constraint, which is $\alpha_{1}=1$ (guarantees that $\left.\hat{B}_{1}\left(q^{-1}, \hat{\boldsymbol{\rho}}\right)=\hat{B}\left(q^{-1}, \hat{\boldsymbol{\rho}}\right)\right)$ to compute $\hat{\alpha}_{i}$ from:

$$
\hat{\alpha}_{i}=\frac{1}{n_{b}+1} \sum_{k=0}^{n_{b}} \frac{\hat{b}_{i, k}}{\hat{b}_{1, k}}
$$

where $\hat{b}_{i, k}$ is the $k$ th coefficient of the polynomial term $B_{i}\left(q^{-1}, \hat{\boldsymbol{\rho}}\right)$.

\section{Comments}

- A simplified version of HCLRIV algorithm named HCLSRIV follows the exact same theory for estimation of Hammerstein models operating in closed-loop with a linear output error process. It is mathematically described by, $C\left(q^{-1}, \boldsymbol{\eta}^{j}\right)=C_{o}\left(q^{-1}\right)=1$ and $D\left(q^{-1}, \boldsymbol{\eta}^{j}\right)=D_{o}\left(q^{-1}\right)=1$. All previous steps remain true except for step 3 which is not anymore required.

- Even if the proposed algorithm performs well, it is not statistically optimal as illustrated in Section V. However, the estimated parameters can be used to initialise a statistically optimal method (prediction error method for example).

\section{NumericAl EXAMPLE}

This section presents numerical illustration of both suggested HCLRIV and HCLSRIV methods. For all presented examples, the non-linear block is a sum of sine functions, i.e. $\gamma_{i}\left(u\left(t_{k}\right)\right)=\sin \left(i . u\left(t_{k}\right)\right), \forall i \in \mathbb{N}$ and the command input $\bar{u}$ considered here is:

$$
\bar{u}\left(t_{k}\right)=\sin \left(u\left(t_{k}\right)\right)-0.5 \sin \left(2 u\left(t_{k}\right)\right)+0.4 \sin \left(3 u\left(t_{k}\right)\right) .
$$

$r_{1}\left(t_{k}\right)$ follows a uniform distribution with values between -2 and 2 while $r_{2}\left(t_{k}\right)=0(N=2000)$. The linear model and controller assuming a zero order hold on the input are given as:

$$
\begin{aligned}
G_{o}(q) & =\frac{0.0997 q^{-1}-0.0902 q^{-2}}{1-1.8858 q^{-1}+0.9048 q^{-2}} \\
H_{o}(q) & =\frac{1+0.5 q^{-1}}{1-0.85 q^{-1}} \\
C_{c}(q) & =\frac{10.75-9.25 q^{-1}}{1-q^{-1}}
\end{aligned}
$$


The models considered for estimation are:

$$
\mathcal{M}_{H C L R I V}\left\{\begin{array}{l}
G(q, \boldsymbol{\rho})=\frac{b_{1} q^{-1}+b_{2} q^{-2}}{1+a_{1} q^{-1}+a_{2} q^{-2}}, \\
H(q, \boldsymbol{\eta})=\frac{1+c_{1} q^{-1}}{1+d_{1} q^{-1}}, \\
f\left(u\left(t_{k}\right)\right)=\sin \left(u\left(t_{k}\right)\right)+\sum_{i=2}^{3} \alpha_{i} \sin \left(i . u\left(t_{k}\right)\right)
\end{array}\right.
$$

for the HCLRIV method and

$$
\mathcal{M}_{H C L S R I V}\left\{\begin{array}{l}
G(q, \boldsymbol{\rho})=\frac{b_{1} q^{-1}+b_{2} q^{-2}}{1+a_{1} q^{-1}+a_{2} q^{-2}}, \\
H(q, \boldsymbol{\eta})=1, \\
f\left(u\left(t_{k}\right)\right)=\sin \left(u\left(t_{k}\right)\right)+\sum_{i=2}^{3} \alpha_{i} \sin \left(i . u\left(t_{k}\right)\right)
\end{array}\right.
$$

for the HCLSRIV method.

As pointed out in Section III the proposed estimator is not optimal due to redundancy in the regressor. For illustration purposes, the proposed methods are compared to the parameters of the linear plant process identified using a prediction error minimisation method (PEMlin, OElin) assuming that $\alpha_{i}$ are known. The problem reduces therefore to the identification of a linear model where the input is $\bar{u}\left(t_{k}\right)$ and the output is $y\left(t_{k}\right)$.

The model considered for the PEM identification using the PEM method from the MATLAB identification toolbox is then:

$$
\mathcal{M}_{\text {PEMlin }}\left\{\begin{aligned}
G(q, \boldsymbol{\rho}) & =\frac{b_{1} q^{-1}+b_{2} q^{-2}}{1+a_{1} q^{-1}+a_{2} q^{-2}}, \\
H(q, \boldsymbol{\eta}) & =\frac{1+c_{1} q^{-1}}{1+d_{1} q^{-1}}, \\
f\left(u\left(t_{k}\right)\right) & =\sin \left(u\left(t_{k}\right)\right)-0.5 \sin \left(2 u\left(t_{k}\right)\right) \\
& +0.4 \sin \left(3 u\left(t_{k}\right)\right)
\end{aligned}\right.
$$

for the PEMlin method.

The model considered for the PEM identification using the $\mathrm{OE}$ method from the MATLAB identification toolbox is then:

$$
\mathcal{M}_{\text {OElin }} \begin{cases}G(q, \boldsymbol{\rho}) & =\frac{b_{1} q^{-1}+b_{2} q^{-2}}{1+a_{1} q^{-1}+a_{2} q^{-2}} \\ H(q, \boldsymbol{\eta}) & =1 \\ f\left(u\left(t_{k}\right)\right) & =\sin \left(u\left(t_{k}\right)\right)-0.5 \sin \left(2 u\left(t_{k}\right)\right) \\ & +0.4 \sin \left(3 u\left(t_{k}\right)\right)\end{cases}
$$

for the OElin method.

A Monte-Carlo simulation of 100 runs $\left(N_{\exp }=100\right)$ with a new noise realization for each run is accomplished under a signal to noise ratio (SNR) of $10 \mathrm{~dB}$ with:

$$
\mathrm{SNR}=10 \log \left(\frac{P_{\grave{y}}}{P_{e}}\right),
$$

$P_{g}$ being the average power of signal $g$. The number of samples is $N=2000$. Table I exhibits the mean value of the estimated parameters, their standard deviation and their normalised root mean square error (RMSE) defined as:

$$
\operatorname{RMSE}\left(\hat{\theta}_{j}\right)=\sqrt{\frac{1}{N_{\text {exp }}} \sum_{i=1}^{N_{\text {exp }}}\left(\frac{\theta_{j}^{o}-\hat{\theta}_{j}(i)}{\theta_{j}^{o}}\right)^{2}},
$$

with $\hat{\theta}_{j}$ the $j$ th component of the parameter vector $\boldsymbol{\theta}$.

On the one hand it can be seen in Table I that even if the noise model assumption is false, which is the case for the HCLSRIV and OElin methods in this example, the refined IV method gives a parameter estimation centered on the true value with a correct estimated parameter variance (RMSE remaining under $16 \%$ ), while the prediction error based method OElin estimates are strongly biased and have RMSE near $30 \%$. This fact makes HCLSRIV a very interesting method for practical applications where the noise dynamic is not known: by modelling a white noise added to the output, the number of parameters to estimate is reduced in comparison to a Box-Jenkins model identification.

On the other hand, the presented HCLRIV method is not optimal due to the redundancy in the regressor but exposes RMSE in estimated parameters under $11 \%$. It can be noticed however that the estimated parameter variances are close to those from PEMlin estimates: this may therefore be seen as an acceptable achievement since in the PEMlin case, the non-linear part is supposed to be known.

\section{CONCLUSION}

The theory of refined instrumental variable was applied to a non-linear closed-loop model composed of a known linear controller, a linear dynamic Box-Jenkins transfer function and a non-linear function defined as the sum of known basis functions. The proposed estimator is not statistically optimal but it was shown on some given example that the variance of estimated parameters is close to the one obtained from the linear optimal PEM estimator. The proposed method can be therefore used as a good starting point for some statistically optimal PEM methods which are known to be sensitive to the initialisation stage. In case the noise model assumed is false, the proposed IV method still converges while the PEM based methods do not. Some further work will be dedicated to blind estimation problems, where the non-linear basic functions $\gamma_{i}$ are a priori not known.

\section{REFERENCES}

[1] E-W. Bai. A blind approach to the Hammerstein-Wiener model identification. Automatica, 38, Issue 6:967-979, 2002.

[2] F. De Bruyne, B. D. O. Anderson, and I. D. Landau. Recursive identification of nonlinear plants operating in closed loop using kernel representations. Automatica, 38, Issue 11:2021-2027, November 2002.

[3] J. de Jesus Rubio and W. Yu. Nonlinear system identification with recurrent neural networks and dead-zone kalman filter algorithm. Neurocomputing, 70, Issues 13-15:2460-2466, 2007.

[4] F. Ding and T. Chen. Identification of Hammerstein nonlinear ARMAX systems. Automatica, 41, Issue 9:1479-1489, September 2005.

[5] U. Forssell and L. Ljung. Closed-loop identification revisited. Automatica, 35(7):1215-1241, 1999. 
TABLE I

Estimation Results For DifFerent Models

\begin{tabular}{|c||c|c|c|c|c|c|c|c|c|}
\hline method & & $b_{1}$ & $b_{2}$ & $a_{1}$ & $a_{2}$ & $\alpha_{1}$ & $\alpha_{2}$ & $c_{1}$ & $d_{1}$ \\
\hline \hline & true value & 0.0997 & -0.0902 & -1.8858 & 0.9048 & -0.5000 & 0.4000 & 0.5000 & -0.8500 \\
\hline \hline \multirow{3}{*}{ PEMlin } & $\operatorname{mean}(\hat{\theta})$ & 0.0998 & -0.0901 & -1.8857 & 0.9028 & $\mathrm{X}$ & $\mathrm{X}$ & 0.4918 & -0.8603 \\
\cline { 2 - 10 } & $\operatorname{std}(\hat{\theta})$ & 0.0009 & 0.0025 & 0.0247 & 0.0208 & $\mathrm{X}$ & $\mathrm{X}$ & 0.0208 & 0.0312 \\
\cline { 2 - 10 } & $\mathrm{RMSE}$ & 0.0089 & 0.0280 & 0.0131 & 0.0229 & $\mathrm{X}$ & $\mathrm{X}$ & 0.0421 & 0.0365 \\
\hline \hline \multirow{3}{*}{ OElin } & $\operatorname{mean}(\hat{\theta})$ & 0.0693 & -0.0653 & -1.8655 & 0.8867 & $\mathrm{X}$ & $\mathrm{X}$ & $\mathrm{X}$ & $\mathrm{X}$ \\
\cline { 2 - 10 } & $\operatorname{std}(\hat{\theta})$ & 0.0016 & 0.0019 & 0.0186 & 0.0171 & $\mathrm{X}$ & $\mathrm{X}$ & $\mathrm{X}$ & $\mathrm{X}$ \\
\cline { 2 - 10 } & $\mathrm{RMSE}$ & 0.2959 & 0.2686 & 0.0141 & 0.0267 & $\mathrm{X}$ & $\mathrm{X}$ & $\mathrm{X}$ & $\mathrm{X}$ \\
\hline \hline \multirow{3}{*}{ HCLSRIV } & $\operatorname{mean}(\hat{\theta})$ & 0.0978 & -0.0894 & -1.8715 & 0.8927 & -0.4893 & 0.4006 & $\mathrm{X}$ & $\mathrm{X}$ \\
\cline { 2 - 10 } & $\operatorname{std}(\hat{\theta})$ & 0.0100 & 0.0138 & 0.0943 & 0.0912 & 0.0774 & 0.0495 & $\mathrm{X}$ & $\mathrm{X}$ \\
\cline { 2 - 10 } & $\mathrm{RMSE}$ & 0.1010 & 0.1588 & 0.0520 & 0.1042 & 0.1554 & 0.1230 & $\mathrm{X}$ & $\mathrm{X}$ \\
\hline \hline \multirow{3}{*}{ HCLRIV } & $\operatorname{mean}(\hat{\theta})$ & 0.1004 & -0.0895 & -1.8862 & 0.8923 & -0.5024 & 0.4015 & 0.4959 & -0.8515 \\
\cline { 2 - 9 } & $\operatorname{std}(\hat{\theta})$ & 0.0031 & 0.0090 & 0.0829 & 0.0799 & 0.0182 & 0.0153 & 0.0249 & 0.0310 \\
\cline { 2 - 9 } & $\mathrm{RMSE}$ & 0.0313 & 0.1035 & 0.0457 & 0.0915 & 0.0367 & 0.0381 & 0.0496 & 0.0365 \\
\hline
\end{tabular}

[6] K. Fujimoto, B. D. O. Anderson, and F. De Bruyne. A parametrization for closed-loop identification of nonlinear systems based on differentially coprime kernel representations. Automatica, 37, Issue 12:18931907, December 2001.

[7] M. Gilson, H. Garnier, P.C. Young, and P. Van den Hof. Refined instrumental variable methods for closed-loop system identification methods. 15th IFAC Symposium on System Identification, Saint-Malo, France, June 2009.

[8] M. Gilson and P. Van den Hof. On the relation between a biaseliminated least-squares (BELS) and an IV estimator in closed-loop identification. Automatica, 37(10):1593-1600, 2001.

[9] M. Gilson and P. Van den Hof. Instrumental variable methods for closed-loop system identification. Automatica, 41(2):241-249, 2005.

[10] I. D. Landau, B. D. O. Anderson, and F. De Bruyne. Recursive identification algorithms for continuous-time nonlinear plants operating in closed loop. Automatica, 37, Issue 3:469-475, March 2001.

[11] Z. Q. Lang, S. A. Billings, R. Yue, and J. Li. Output frequency response function of nonlinear Volterra systems. Automatica, 43, Issue 5:805-816, May 2007.

[12] V. Laurain, M. Gilson, H. Garnier, and P. C. Young. Refined instrumental variable methods for identification of Hammerstein continuoustime Box-Jenkins models. In 47th Conference on Decision and Control, Cancun - Mexico, December 9 - December 112008.

[13] L. Ljung. System identification : theory for the user - Second Edition. Prentice-Hall, 1999.

[14] O. Nelles. Nonlinear system identification. Springer-Verlag, Berlin, 2001

[15] Z. K. Peng, Z. Q. Lang, and S. A. Billings. Linear parameter estimation for multi-degree-of-freedom nonlinear systems using nonlinear output frequency-response functions. Mechanical Systems and Signal Processing, 21, Issue 8:3108-3122, november 2007.

[16] A. S. Poznyak and L. Ljung. On-line identification and adaptive trajectory tracking for nonlinear stochastic continuous time systems using differential neural networks. Automatica, 37, Issue 8:1257-1268, August 2001.

[17] T. Söderström and P. Stoica. Instrumental Variable Methods for System Identification. Springer-Verlag, New York, 1983.

[18] T. Söderström and P. Stoica. System identification. Prentice-Hall, 1989.

[19] T. Söderström, P. Stoica, and E. Trulsson. Instrumental variable methods for closed-loop systems. In 10th World IFAC Congress, pages 363-368, Munich - Germany, 1987.

[20] P. Van den Hof. Closed-loop issues in system identification. Annual Reviews in Control, 22:173-186, 1998.

[21] H. Wang, K. Ju, and K. H. Chon. Closed-loop nonlinear system identification via the vector optimal parameter search algorithm: Application to heart rate baroreflex control. Medical Engineering \& Physics, 29, Issue 4:505-515, May 2007.
[22] P. C. Young. An instrumental variable method for real-time identification of a noisy process. Automatica, 6:271-287, 1970.

[23] P. C Young. Recursive Estimation and Time-Series Analysis. SpringerVerlag, Berlin, 1984.

[24] P. C. Young. Nonlinear Dynamics and Statistics, chapter The identification and estimation of nonlinear stochastic systems, pages 127-166. Birkhauser: Boston, 2001.

[25] W. X. Zheng. Application of bels based methods in direct identification of linear systems from closed loop data. In IEEE, editor, 42nd IEEE Conference on Decision and Control, pages 4539-4544, Hawaï - USA, December 2003. 